\title{
LIQUID CRYSTALLINE PROPERTIES OF SOME MONOMERIC AZO- AND AZOXYBENZENES AND THEIR POLYMERS
}

\author{
I. I. KONSTANTINOV
}

Topchiev Institute of Petrochemical Synthesis, Academy of Sciences of the U.S.S.R., Moscow U.S.S.R.

\begin{abstract}
Résumé. - On a étudié le mésomorphisme des p-acryloyl- et p-méthacryloyloxy-p'-substitués, azo- et azoxybenzènes. Les polymères, obtenus par polymérisation radicalaire, forment des phases mésomorphes au-delà de $T_{\mathrm{g}}$. D'après les données des rayons $\mathrm{X}$, ces polymères ont un caractère smectique. Il n'y a pas de corrélation entre le comportement thermique des monomères et des polymères. Les propriétés optiques des polymères dépendent de la nature du solvant. On suppose que le mésomorphisme des polymères est provoqué par l'interaction entre les groupes latéraux mésogènes de la macromolécule.
\end{abstract}

\begin{abstract}
We have studied the mesomorphism of p-acryloyl- and p-methacryloyl-oxy-p'substituted azo- and azoxybenzenes. Polymers, obtained by free radical polymerization of these compounds in solution, give anisotropic melts at $T_{\mathrm{g}}$. According to X-ray diffraction data the polymers are characterized by a smectic structure. There is no correlation between the thermal behaviour of monomers and polymers. The optical properties of glassy polymers depend on the nature of solvent. Mesomorphism in these polymers is probably due to the interaction between mesogenic side groups within the macromolecule.
\end{abstract}

The characteristic feature of macromolecules is known to be flexibility which depends on the chemical structure of units and governs the physical properties of polymers. It follows that liquid crystalline behaviour of polymers, in particular the polymers with mesogenic side groups, would depend on chemical structure of monomers, including the nature of the polymerizable group. Naturally, the structure of a monomer is to satisfy the principal requirements for mesomorphic compounds [1].

At present some theoretical conclusions are available, based on extensive experimental data regarding mesomorphism of low molecular weight mesophases, depending on the structure of molecules, particularly on the nature of terminal groups and linkages. They enable to synthesize new compounds with desired liquid crystalline properties. Lack of similar information for polymeric liquid crystals is due to, first of all, the fact that intense investigations at such polymers were begun quite recently.

The present paper is devoted to the study of mesomorphism of polymers depending on both chemical structure of the main chain and para-substitutent of the mesogenic side group. It is also of interest to compare the mesomorphic behaviour of monomers and their saturated analogues.

For this purpose some p-acryloyl- and p-methacryloyloxy $\mathrm{p}^{\prime}$-substituted azo- and azoxybenzenes were prepared, shown in table I.
1. Mesomorphous behaviour of monomers. - Of the twelve monomeric azomethines, described by Ringsdorf et al. [2], only five were mesomorphic : four acrylates and one methacrylate. The acrylates proved to have wider mesophase range than their saturated analogues-propionates [3].

In case of azo compounds, acrylates and propionates are inclined to mesomorphism to a greater extent than methacrylates. This tendency increases in replacing the azo group by the azoxy group. The acrylate group as compared with propionate one influences a mesophase thermal stability of azobenzenes in different way depending on the nature of $p^{\prime}$-substitutent : the $p^{\prime}$-alkoxy substituted acrylates and propionates [4] have practically the same clearing temperature, $T_{\mathrm{cl}}$; whereas the acetyl substituted acrylate has higher $T_{\mathrm{cI}}$ than its saturated analogue; melting temperature $\left(T_{\mathrm{m}}\right)$ of the ethyl substituted acrylate is lower than $T_{\mathrm{m}}$ of the propionate.

Azoxy monomers are characterized by higher thermal stability of mesophase (except compound 4) than the corresponding azo monomers, as it is the case with the majority of known azoxy benzenes with saturated $\mathrm{p}, \mathrm{p}^{\prime}$-substitutents [4].

2. Mesomorphism of polymers. - The polymers were obtained by free radical polymerization in dioxane solution at $60^{\circ} \mathrm{C}$ using benzoyl peroxide as a initiator. The polymerization products were 
TABLE I

Structure and properties of monomers and polymers

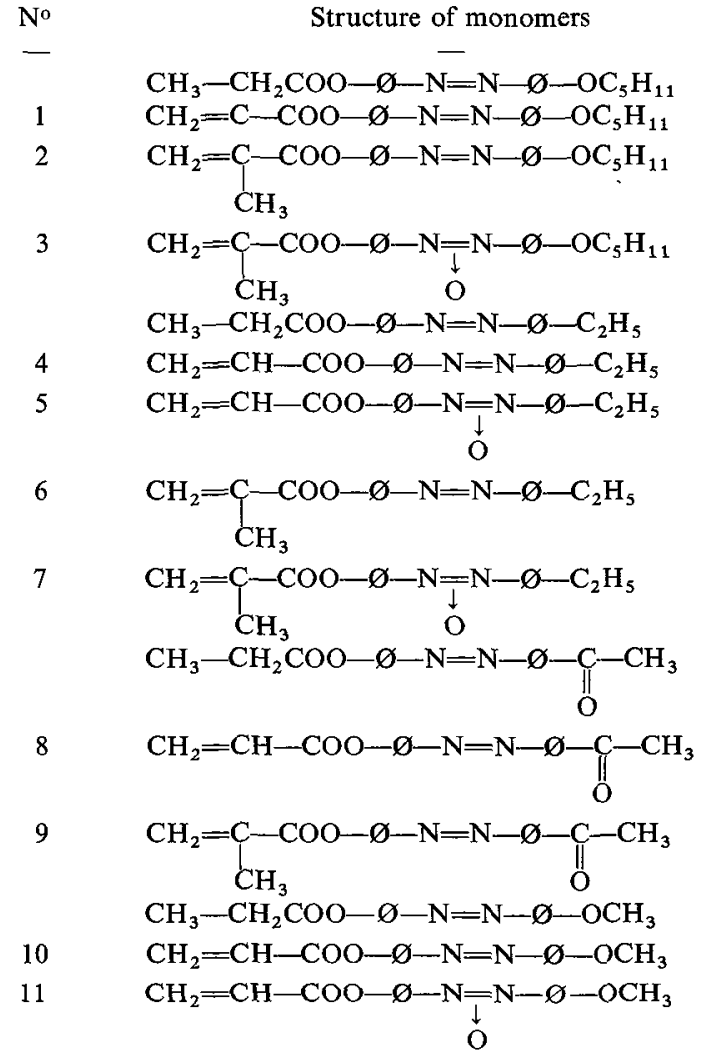

(*) Amorphous reflexion.

precipitated into acetone and dried in vacuo. In similar manner some copolymers with n-butylmethacrylate (BMA) were obtained. Their composition was determined from the azo unit concentration calculated on their optical density at $\lambda_{\max }$ in chloroform solution and from elemental analysis.

Thermomechanical investigations were carried out by the static loading $13 \mathrm{k} / \mathrm{cm}^{2}$ at heating rate $2 \% / \mathrm{min}$.

The temperature range of the liquid crystalline state was identified by a polarizing microscope equiped with a hot stage. X-ray diffraction patterns were recorded by means of a flat camera at room temperature.

DTA and TGA were performed with a derivatograph at heating rate $3 \% \mathrm{~min}$.

According to the x-ray data polymers and copolymers show a smectic structure [5, 6]. A broad reflexion in the wide angle region is attributed to the short range order of the mesogenic side groups. Some sharp reflexions in the small angle region are due to regular packed smectic layers formed by the side groups. The position and width of the halo vary in

( $\left.{ }^{1}\right)$ More detailed information on the copolymers and X-ray diffraction data will be reported in a separate paper.

\begin{tabular}{|c|c|c|c|c|c|c|c|c|c|}
\hline \multirow{3}{*}{\multicolumn{5}{|c|}{$\begin{array}{c}\text { Monomer phase } \\
\text { transition, }{ }^{\circ} \mathrm{C} \\
-\end{array}$}} & \multicolumn{2}{|c|}{ Polymer } & \multirow{2}{*}{\multicolumn{3}{|c|}{$\begin{array}{c}\text { X-ray data of polymers } \\
\AA\end{array}$}} \\
\hline & & & & & & \multirow{3}{*}{$\overline{-}^{T_{\mathrm{i}}}$} & & & \\
\hline & & & & & & & \multicolumn{3}{|c|}{-} \\
\hline$k$ & 86 & $n$ & 114 & $i$ & & & & & \\
\hline$k$ & 67 & $n$ & 112 & $i$ & 75 & $>270$ & 17.7 & 12.6 & 4.5 \\
\hline$k$ & & & 92 & $i$ & 135 & $>270$ & 25.2 & 11.8 & $4.6\left(^{*}\right)$ \\
\hline$k$ & 76 & $n$ & 89 & $i$ & 120 & 265 & 25.2 & 12.6 & $4.6\left(^{*}\right)$ \\
\hline$k$ & & & 66 & $i$ & & & & & \\
\hline$k$ & & & 50 & $i$ & 90 & $>270$ & 25.2 & 8.8 & $4.6\left(^{*}\right)$ \\
\hline$k$ & 55 & $n$ & 77 & $i$ & & [9] & & & \\
\hline$k$ & & & 53 & $i$ & 160 & $>270$ & 25.2 & 9.6 & $4.9\left(^{*}\right)$ \\
\hline$k$ & & & 75 & $i$ & 100 & $>270$ & & & \\
\hline$k$ & 114 & $s$ & 119 & $i$ & & & & & \\
\hline$k$ & 133 & $n$ & 142 & $i$ & 100 & $>270$ & 11.3 & $\begin{array}{l}8.0 \\
4.0\left(^{*}\right)\end{array}$ & $\begin{array}{l}6.3 \\
3.2\end{array}$ \\
\hline$k$ & & & 154 & $i$ & & & 8.8 & 5.6 & 4.3 \\
\hline$k$ & 91 & $n$ & 117 & $i$ & & [3] & & & \\
\hline$k$ & 97 & $n$ & 119 & $i$ & 90 & $>270$ & 25.2 & 8.8 & $4.6\left(^{*}\right)$ \\
\hline$k$ & 87 & $n$ & 147 & & & 10] & & & \\
\hline
\end{tabular}

introducing the nonmesogenic BMA units in macromolecules $\left({ }^{1}\right)$. A similar change of the parameters of the halo was observed in heating the poly-(methacryloyloxybenzilidene-p'-ethoxyaniline) [5] above $T_{\mathrm{g}}$. This is due to increasing distance between the mesogenic groups. The position of the sharp reflexions of the copolymers was constant, but their intensity was reduced as the BMA unit content increased. Similar data have been reported by Blumstein et al. [7] for some copolymers of cholesteryl methacrylate with alkylmethacrylates. In this case some increase in the intensity of the small angle reflexion for the copolymers with small content of nonmesogenic units was also observed. This appeares to be concerned with favourable conditions for packing layers consisting of extensive cholesterol groups.

The crystalline structure of polymer 9 is evidenced by the presence of sharp reflexions only on the X-ray pattern. Polymer 9 formed in polymerization fell out from the solution and was unsolvable in many solvents used. Introducing BMA units in the macromolecules result in the lattice disturbance, as a result the copolymers have one halo and two sharp reflexions.

According to the degree of order, polymer 9 is followed by polymer 8 . The latter has five sharp 
reflections in addition to a broad reflexion. The other polymers are characterized by two sharp reflexions and a halo.

All the polymers (except polymer 9) pass into liquid crystalline state at glass temperature, $T_{\mathrm{g}}$. As follows from table I $T_{\mathrm{g}}$ 's of the polyacrylates are lower than $T_{\mathrm{g}}$ 's of the polymethacrylates with the same $\mathrm{p}^{\prime}$-substitutents.

It has been supposed that the interaction between mesogenic groups within macromolecule would increase in order for increasing a polarisability anisotropy of $p^{\prime}$-substitutents as it took place for monomers. However there is not any correlation between thermal properties of monomers and those of polymers.

The $T_{\mathbf{g}}$ of polymer 6 is the highest in spite of the fact that the $T_{\mathrm{m}}$ of the original monomer is lower than $T_{\mathrm{m}}$ 's of the other methacrylates. With the polyacrylates, polymers 4 and 10 have the same $T_{\mathrm{g}}$, although the difference between $T_{\mathrm{m}}$ 's of the original monomers is $69^{\circ} . T_{\mathrm{g}}$ decreases in replacing the azo group by the azoxy group, which is clearly seen from the comparison of $T_{\mathrm{g}}$ 's of polymers 6 and 7 .

The rigidity of the macromolecules, and hence $T_{\mathrm{g}}$, seems to be due to chemical structure of the main chain and the interaction between smectic layers. Mesomorphism of the polymers, however, appears to depend on the interaction between mesogenic side groups within macromolecule. This interaction is exhibited in introducing the nonmesogenic units in macromolecules.

Liquid crystalline state of copolymers of 2 with BMA, for example, is observed only equimolar composition, whereas the birefringence of the copolymers of 6 with BMA has not already been observed at the BMA unit content of $34 \%$ mole.

According to TGA data decomposition and depoly- merization of the polymers take place at $270^{\circ} \mathrm{C}$, i.e. the polymers (except polymer 3 ) are still in the liquid crystalline state. Polymer 3 passes into isotropic melt at $265^{\circ} \mathrm{C}\left(T_{\mathrm{i}}\right)$. This transition is accompanied by thermal effect. On cooling the isotropic melt of polymer 3 the optical anisotropy occures again which remains in the glassed sample.

Similarly, optical anisotropy arises in the glassed polymers prepared in the form of films cast from chloroform or dichlorethane solutions. The films of polymers 2 and 3 , for example, cast from benzene solution show birefringence after evaporation of the solvent without heating. The fact that the intrinsic viscosity of polymer 6 , for example, depends on the solvents $\left(0.915 \mathrm{CHCl}_{3}, 0.685\right.$ dichlorethane, 0.645 benzene), points to different conformations which macromolecules acquire in solution. This conformations appeare to remain to some extent after evaporation of solvent, thus affecting the optical properties of the polymers.

From the above data and data of other workers it may be concluded that mesomorphism of the original monomers is not necessary for preparation of liquid crystalline polymers.

Liquid crystalline state range of polymers depends on :

- the nature of mesogenic group,

- chemical structure of the main chain,

- configuration of the main chain as it was clearly shown by Magagnini and coworkers [8],

- introducing nonmesogenic units in macromolecules.

Liquid crystalline state of the polymers and copolymers under study results from cooperative interaction of mesogenic units within the macromolecules with certain conformations of the main chain.

\section{References}

[1] Gray, G. W., Molecular Structure and the Properties of Liquid Crystals (London, New York, Academic Press) 1962.

[2] Perplies, E., Ringsdorf, H., Wendorff, J. H., Makromol. Chem. 175 (1974) 553.

[3] Demus, D., Demus, H., ZaschKe, H., Flüssige Kristalle in Tabellen, VEB Deutscher Verlag für Grundstoffindustrie, Leipzig, 1974.

[4] McCaffrey, M. T., Castellano, J. A., Mol. Cryst. Liq. Cryst. 18 (1972) 209.

[5] Wendorff, J. H., Finkelmann, H., Ringsdorf, H., ACS Polymer Preprints 18 (1977) 5.
[6] Clough, S. B., Blumstein, A., De Vries, A., ACS Polymer Prepints 18 (1977) 1.

[7] Osada, Y., Blumstein, A., J. Polymer Sci. ; Polymer Letters Ed. 15 (1977) 761.

[8] Newman, B. A., Frosini, V., Magagnini, P. L., ACS Polymer Preprints 18 (1977) 9.

[9] Cser, F., Nyitrai, K., Seyfried, E., Hardy, Gy., Europ. Polymer J. 13 (1977) 679.

[10] Lecoin, D., Hochapfel, A., Viovy, R., Mol. Cryst. Liq. Cryst. 31 (1975) 233. 